\title{
Validation of a simple isocratic HPLC-UV method for rifampicin and isoniazid quantification in human plasma
}

\author{
Laura Carolina Luciani-Giacobbe ${ }^{1}$, María Laura Guzman ${ }^{1}$, Rubén Hilario Manzo ${ }^{1}$, María Eugenia Olivera ${ }^{1 *}$ \\ Unidad de Investigación y Desarrollo en Tecnología Farmacéutica (UNITEFA), CONICET and Departamento de Ciencias Farmacéuticas, Facultad de \\ Ciencias Químicas, Universidad Nacional de Córdoba, Ciudad Universitaria, X5000HUA Córdoba, Argentina.
}

\begin{tabular}{|c|c|}
\hline ARTICLE INFO & ABSTRACT \\
\hline Article history: & \multirow{5}{*}{$\begin{array}{l}\text { A simple and selective reversed phase HPLC-UV method for rifampicin and isoniazid quantification in human plasma } \\
\text { was developed and validated. The method consisted of drug extraction with trichloroacetic acid and organic solvent } \\
\text { followed by derivatization of isoniazid. Using an isocratic mode, rifampicin was analyzed on a C18 }(250 \times 4.6 \mathrm{~mm}, 5 \\
\mu \mathrm{m}) \text { column at } 339 \mathrm{~nm} \text {, while isoniazid was analyzed on a C } 8(250 \times 4.6 \mathrm{~mm}, 5 \mu \mathrm{m}) \text { column at } 273 \mathrm{~nm} \text {. All validation } \\
\text { parameters fulfilled the FDA requirements, as the method was accurate (bias } \%<10.26) \text {, precise }(\mathrm{CV} \%<10.39) \text { and } \\
\text { linear from } 0.31 \text { to } 37.80 \mu \mathrm{g} / \mathrm{mL} \text { of rifampicin and } 0.89 \text { to } 71.36 \mu \mathrm{g} / \mathrm{mL} \text { of isoniazid. The samples remained stable } \\
\text { during the usual processing and analysis times and also during the two freeze/thaw cycles. The recovery of both } \\
\text { analytes was reproducible }(\mathrm{CV} \%<11.2) \text { in the range of } 97.3-99.6 \% \text { of rifampicin and } 89.8-96.6 \% \text { of isoniazid. } \\
\text { The low volume of plasma necessary for the quantification of the samples }(750 \mu \mathrm{L} \text { in total }) \text { and the low limit of } \\
\text { quantification }(0.31 \mu \mathrm{g} / \mathrm{mL} \text { for rifampicin and } 0.89 \mu \mathrm{g} / \mathrm{mL} \text { for isoniazid) made this method useful for carrying out } \\
\text { pharmacokinetic tests both in humans or animal models. In addition, the method can be successfully applied for } \\
\text { bioavailability studies or drug monitoring in tuberculosis treatment. }\end{array}$} \\
\hline Received on: $02 / 03 / 2018$ & \\
\hline Accepted on: 11/06/2018 & \\
\hline Available online: $30 / 07 / 2018$ & \\
\hline $\begin{array}{l}\text { Key words: } \\
\text { rifampicin, isoniazid, } \\
\text { human plasma, HPLC-UV, } \\
\text { validation, tuberculosis. }\end{array}$ & \\
\hline
\end{tabular}

\section{INTRODUCTION}

The treatment of tuberculosis is currently complex and prolonged (Beltrame et al., 2014; World Health Organization, 2016), and consists of the administration of rifampicin (RIF) and isoniazid (INH) in a fixed-dose combination (FDC) as immediaterelease solid dosage forms (tablets or capsules) for 6 months. They are also associated with ethambutol (ETA) and pyrazinamide (PIR) within the first 2 months (World Health Organization, 1997).

Although the treatment is still effective ( $\mathrm{Lu}$ et al., 2017), it has multiple associated problems that compromise its effectiveness. One of the main drawbacks of the treatment is the low and variable bioavailability of RIF, which is mainly related to the poor wettability and the slow dissolution rate of the solid, due to the different properties of RIF polymorphs, its hydrophobicity, and $\mathrm{pH}$-dependent solubility. The influence of some excipients

\section{${ }^{*}$ Corresponding Author}

María Eugenia Olivera, Haya de la Torre y Medina Allende. Edificio Ciencias 2. Ciudad Universitaria (X5000HUA), Córdoba, Argentina. E-mail:meoliver@fcq.unc.edu.ar on the performance of the solid dosage form, the inter-individual variability in the absorption and metabolism of RIF, are also associated with bioavailability problems (Becker et al., 2009; Singh et al., 2006). Additionally, its degradation at gastric $\mathrm{pH}$, accelerated by the presence of INH in the formulation, has a negative impact on the bioavailability (Singh et al., 2006).

As RIF and INH are still effective, overcoming the main technological drawbacks of these therapeutic agents in order to enhance compliance and adherence as well as improve the effectiveness of the drugs is an interesting challenge for the pharmaceutical technology area.

In order to ensure an adequate performance of current and innovative formulations, the availability of validated bioanalytical methods is important for the evaluation of their bioavailability (Agrawal and Panchagnula, 2005) as well as for therapeutic drug monitoring (Alsultan and Peloquin, 2014; Verbeeck et al., 2016).

Several bioanalytical methods have been proposed for the determination of RIF and INH in plasma (Desai and Shah, 2015; Goutal et al., 2016; Khuhawar and Rind, 2002; Prasanthi et al., 2015; Walubo et al., 1994) including HPLC or UHPLC masss 
pectrometry (Avachat and Bhise, 2011; Hee et al., 2015; Prasad and Singh, 2009) and HPLC UV with gradient elution and a flowrate program (Ahmad et al., 2006; Chellini et al., 2015; Goutal et al., 2016; Walubo et al., 1994; Zhou et al., 2010).

Liquid chromatography coupled to mass spectrometry (LC-MS/MS) instrumentation is selective and sensitive. However, it is expensive and requires highly skilled expertise that restricts its use primarily to high volume or research laboratories. Therefore, HPLC-UV is still the most common and economical method for the simultaneous determinations of anti-tuberculosis drugs. The gradient module allows separating complex samples. However, it is an expensive instrumentation, the methods are complex to develop and transfer, and are generally considered to be inherently slower techniques than isocratic elution, since the column must be equilibrated with at least 10 column volumes of initial eluent before reliable retention can be obtained in the next run (Schellinger and Carr, 2006). Thus, many of these methods cannot be reproduced (Kim et al., 2015; Zhou et al., 2010).

Just a few isocratic HPLC methods have been published, and none of them have been validated for RIF and INH quantification in pharmacokinetic studies. These methods are inexpensive and accessible to developing countries, in which tuberculosis is more prevalent.

In this context, there is a necessity to develop and validate an HPLC method for the reliable quantification of RIF and INH in plasma samples. The purpose of this study is to develop a simple, reproducible isocratic HPLC-UV method for the determination of RIF and INH concentration in human plasma and validate it while fulfilling international guidelines.

\section{MATERIALS AND METHODS}

\section{Chemicals and materials}

RIF and INH of pharmaceutical grade were acquired from Parafarm ${ }^{\circledR}$ (Argentina) and Droguería Libertad (Argentina), respectively. Human plasma was kindly donated by Laboratorio de Hemoderivados, Córdoba-Argentina. Rifamycin (RIM) and atenolol (AT), of pharmaceutical grade, were purchased from Parafarm ${ }^{\circledR}$ (Argentina) and used as internal standards. A derivatizing agent of INH, p-hydroxybenzaldehyde (pro-analysis grade, Sigma-Aldrich, Germany), was used. For the sample processing and HPLC quantification, acetonitrile (HPLC grade,

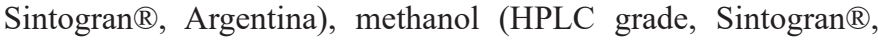
Argentina) and Milli Q water were used.

All other reagents were of pro-analysis quality.

\section{HPLC apparatus}

The instrument consisted of a Waters 1525 pump, a Waters 717 plus autosampler, a Waters 1500 series column heater and a Waters 2996 photo array detector (PDA) (Waters Corp., Milford, USA). Data acquisition was performed by the Empower Software ${ }^{\circledR}$ data registration.

\section{Chromatographic conditions}

System 1

The analytical column was a reversed-phase Luna C18 (250 $\mathrm{mm} \times 4.6 \mathrm{~mm}$ i.d., $5 \mu \mathrm{m}$ particle size, Phenomenex, Torrance, $\mathrm{CA}$, USA) maintained in the column oven at $30^{\circ} \mathrm{C}$ and protected by a Phenomenex ${ }^{\circledR}$ Security Guard precolumn. The mobile phase consisted of methanol: potassium phosphate buffer ( $\mathrm{pH} 7.00 ; 0.02$ M) $(75: 25, \mathrm{v} / \mathrm{v})$. The elution was carried out isocratically at a flow rate of $0.5 \mathrm{~mL} / \mathrm{min}$. The mobile phase was filtered through a $0.45 \mu \mathrm{m}$ Millipore Durapore ${ }^{\circledR}$ filter (Billerica, MA, USA) and degassed by vacuum prior to use.

System 2

The analytical column was a reversed-phase Luna C8 $(250 \mathrm{~mm} \times 4.6 \mathrm{~mm}$ i.d., $5 \mu \mathrm{m}$ particle size, Phenomenex, Torrance, CA, USA) maintained in the column oven at $25^{\circ} \mathrm{C}$ and protected by a C8 Phenomenex ${ }^{\circledR}$ Security Guard precolumn. The mobile phase consisted of methanol:water:perchloric acid solution $(70 \% \mathrm{v} / \mathrm{v})$ : tetrabutylammonium hydroxide solution $(40 \% \mathrm{v} / \mathrm{v})(20: 80: 0.05: 0.05, \mathrm{v} / \mathrm{v} / \mathrm{v} / \mathrm{v})$. The elution was carried out isocratically at a flow rate of $1 \mathrm{~mL} / \mathrm{min}$. The mobile phase was filtered through a $0.45 \mu \mathrm{m}$ Millipore Durapore ${ }^{\circledR}$ filter (Billerica, MA, USA) and degassed by vacuum prior to use.

\section{Preparation of standards and quality control samples}

Working solutions of RIF were prepared in MilliQ water in concentrations between 0.16 and $200.00 \mu \mathrm{g} / \mathrm{mL}$. These solutions were kept in light-tight flasks and used immediately. Calibration standards of $0.16 ; 0.31 ; 1.51 ; 4.68 ; 7.56$ and $37.80 \mu \mathrm{g} / \mathrm{mL}$ of RIF were prepared extemporaneously by adding an appropriate volume of each RIF working solution in $1 \mathrm{~mL}$ of human plasma. This range of the standard curve was chosen to reflect the plasma concentrations expected in a typical $24 \mathrm{~h}$ pharmacokinetic profile post administration of 300 or $600 \mathrm{mg}$ of RIF tablets (Avachat and Bhise, 2011; Wang et al., 2013; Xu et al., 2013).

Working solutions of INH were prepared in Milli Q water in concentrations between 0.57 and $230.00 \mu \mathrm{g} / \mathrm{mL}$. These solutions were kept in light-tight flasks stored under refrigeration and used within four weeks (Agrawal et al., 2001). Calibration standards of $0.89 ; 3.57 ; 8.92 ; 17.84 ; 35.68 ; 71.36 \mu \mathrm{g} / \mathrm{mL}$ of INH were prepared extemporaneously by adding an appropriate volume of each INH working solution in human plasma. This range of the standard curve was chosen to reflect the plasma concentrations expected in a typical $24 \mathrm{~h}$ pharmacokinetic profile post administration of 150 or $300 \mathrm{mg}$ of INH tablets (Agrawal et al., 2001; Hee et al., 2015; Wang et al., 2013; Xu et al., 2013).

Quality control samples were prepared at low, medium and high concentrations of RIF $(0.31,1.51$ and $37.80 \mu \mathrm{g} / \mathrm{mL})$ and INH $(0.89,17.84$ and $71.36 \mu \mathrm{g} / \mathrm{mL})$.

\section{Sample preparation}

\section{Determination of RIF}

Sample preparation was performed by protein precipitation of $500 \mu \mathrm{L}$ of calibration standards of human plasma with $1400 \mu \mathrm{L}$ of acetonitrile-water (70:30, v/v) containing ascorbic acid at $179 \mu \mathrm{g} / \mathrm{mL}$ and RIM at $36 \mu \mathrm{g} / \mathrm{mL}$ (which was the internal standard). After vortex and centrifugation for $10 \mathrm{~min}$ (120 Hz, room temperature), $1 \mathrm{~mL}$ of supernatant was collected, placed into a $1.5 \mathrm{~mL}$ polypropylene tube and filtered with a 0.22 $\mu \mathrm{m}$ membrane filter Millipore Durapore ${ }^{\circledR}$ (Billerica, MA, USA). One hundred microliters of this solution were injected into the HPLC system and quantified at $339 \mathrm{~nm}$. 


\section{Determination of INH}

One hundred microliters of AT $(0.16 \% \mathrm{w} / \mathrm{v})$ and 200 $\mu \mathrm{L}$ of a methanolic solution of p-hydroxybenzaldehyde $(1.5 \%$ $\mathrm{w} / \mathrm{v}$ ), which acted as derivatizing agent, were added to $250 \mu \mathrm{L}$ of human plasma samples. Proteins were precipitated with $400 \mu \mathrm{L}$ of $10 \% \mathrm{v} / \mathrm{v}$ trifluoracetic acid solution and $1 \mathrm{~mL}$ of methanol. After vortex and centrifugation for $10 \mathrm{~min}(120 \mathrm{~Hz}$, room temperature), $1.00 \mathrm{~mL}$ of supernatant was filtered with a $0.22 \mu \mathrm{m}$ membrane filter Millipore Durapore ${ }^{\circledR}$ (Billerica, MA, USA). A hundred microliters of this solution were injected into the HPLC system and quantified at $273 \mathrm{~nm}$.

\section{Method validation}

All validation procedures were performed according to US Food and Drug Administration (FDA) guidance for the validation of bioanalytical methods (FDA, 2001). The validation parameters were specificity, linearity, sensitivity, accuracy, precision, recovery and stability in human plasma.

\section{Selectivity}

Selectivity was studied by comparing chromatograms of six blank plasma samples with plasma samples spiked with RIF and INH. Each blank sample was tested for interference, and selectivity was ensured at the lower limit of quantification (LLOQ).

In addition, the resolution ( $\mathrm{R})$ was determined as a measure of separation between the peaks of interest, using equation 1 described in the Farmacopea Argentina (Ministerio de Salud, 2003):

$$
R=\left|\frac{2 *\left(t_{r A}-t_{r I S}\right)}{w_{A}+w_{I S}}\right|,
$$

Equation 1

where $t_{r A}$ y $t_{r I S}$ are the relative retention times (in minutes) and $w_{A}$ and $w_{I S}$ are the peak widths (in minutes) of the analyte of interest (RIF or INH) and their internal standard, respectively. The acceptance criterion was a resolution value $\geq 2$.

\section{Linearity}

Calibration curves were obtained on three different days by analyzing standard plasma samples of each analyte at six concentrations and processed by weighted $(1 / \mathrm{x})$ least squares linear regression. The linearity of each method-matched calibration curve was determined over the designated concentration range.

\section{Accuracy, precision and lower limit of quantification}

The precision (presented as the coefficient of variation; $\mathrm{CV}$ ) and accuracy of the assay were assessed by analyzing quality control samples at three concentrations. Precision is expressed as the coefficient of variation: $\mathrm{CV}=(\mathrm{SD} /$ mean $) \times 100$, and accuracy error is expressed as the bias: [(measured concentration - nominal concentration)/nominal concentration] $\times 100$. The intra-day $\mathrm{CV}$ and accuracy of the method were evaluated based on the analysis of five samples. The CV and accuracy for inter-day assays were assessed at the same concentration and repeated on three different days.

The LLOQ was defined as the lowest concentration of analyte which can be determined with acceptable accuracy and precision. The signals from the analytes found in the LLOQ sample should be at least 5 times greater than the signal of the blank sample (FDA, 2001).

Acceptance criteria were: bias within $\pm 15 \%$ of the nominal value and within- and between-run precision lower than $15 \%$ (except $20 \%$ for the LLOQ).

Recovery

Recovery was assessed at two concentrations for each drug (1.67 and $41.79 \mu \mathrm{g} / \mathrm{mL}$ of RIF and 4.41 and $88.11 \mu \mathrm{g} /$ $\mathrm{mL}$ of INH), by comparing the peak areas of triplicates at each concentration for RIF and INH standards in Milli Q water and standards spiked before protein precipitation in human plasma. Recovery was calculated as the ratio of the mean peak area of an analyte spiked into plasma before extraction and the mean peak area of the same analyte spiked in Milli Q water at the same concentration, multiplied by 100 .

\section{Stability}

Short-term, post-preparative and freeze-thaw stability of the samples was assessed at low and high concentrations for each analyte $(1.67$ and $41.79 \mu \mathrm{g} / \mathrm{mL}$ for RIF and 4.41 and $88.11 \mu \mathrm{g} / \mathrm{mL}$ for INH).

Freeze-thaw stability was determined in triplicate at 1 , 2 and 3 cycles of freeze-thawing. At time zero, after taking an aliquot for quantification, the enriched plasma was separated into $2 \mathrm{~mL}$ Eppendorf tubes and frozen at $-20^{\circ} \mathrm{C}$. After $24 \mathrm{~h}$, samples were thawed at room temperature and kept sheltered from light for about $1 \mathrm{~h}$ to ensure temperature balance. Immediately thereafter, an aliquot was taken, processed and quantified (first freezethawing cycle). This cycle was repeated twice, completing the second and third freeze-thawing cycles. Short-term stability was determined from these plasma samples kept at room temperature for $6 \mathrm{~h}$ (expected time for processing of the samples each day) and quantified by HPLC $(\mathrm{n}=3)$. The post-preparative stability was determined after $24 \mathrm{~h}$ storage at room temperature in the autosampler.

The responses obtained for the fresh samples and those submitted to the stability studies were compared and the acceptance parameter was defined as a bias within $\pm 15 \%$.

\section{RESULTS AND DISCUSSION}

\section{Performance of HPLC system}

Our study separated analytes from plasma sample by protein precipitation with trichloroacetic acid and organic solvents, which was an easy, rapid and convenient method (Unsalan et al., 2005), avoiding liquid-liquid or solid-phase extractions of the drugs, which would increase the sample processing complexity (Balbão et al., 2010; Hee et al., 2015; Walubo et al., 1994).

Panchagnula et al. (1999) quantified RIF and desacetyl rifampicin in human plasma, using an HPLC-UV isocratic method. Thus, the current bioanalytical method was developed from the above chromatographic conditions and small modifications were made to improve the resolution of the chromatographic peaks. An increase in the proportion of methanol in the mobile phase (from 65 to 75 ) decreased the retention time of RIF and the internal standard from 11.9 and $7.9 \mathrm{~min}$ to 5.8 and $4.7 \mathrm{~min}$, respectively. The flow 
rate reduction from 1 to $0.5 \mathrm{~mL} / \mathrm{min}$ allowed a better resolution of RIF relative to RIM (from 2.3 to 3.2) while maintaining the symmetry of the peaks.

Preliminary studies showed that INH, which is a hydrophilic compound, elutes with the front of solvent and plasma impurities. Thus, we performed a derivatization step, which consists in the reaction between the aldehyde group of p-hydroxybenzaldehyde and the hydrazine group of INH to obtain a more hydrophobic INH hydrazone. This strategy was previously informed by Gupta (1988) and allowed to enhance resolution, with sensitive detection of INH (retention time 9.6). This approach is a usual procedure to modify the retention time and permitted INH quantification. In addition to p-hydroxybenzaldehyde, other common INH derivatizing reagents such as cinnamaldehyde, salicylaldehyde, and 2-fluorene-carboxaldehyde have been informed (Agrawal et al., 2001; Gupta, 1988; Unsalan et al., 2005).

Initially, as described in the literature, pyrazinamide was used as an internal standard. However, its chromatographic peak was not well resolved with respect to the solvent front, either using a $150 \mathrm{~mm}$ or $250 \mathrm{~mm}$ column or varying the proportions of methanol:water in the mobile phase from the ratio $(85: 15 \mathrm{v} / \mathrm{v})$ to $(70: 30 \mathrm{v} / \mathrm{v})$. Then, other internal standards of solubility and Log $\mathrm{P}$ similar to the INH hydrazone, such as paracetamol, isonicotinic acid, hydrochlorothiazide and AT were selected. AT was the only compound that did not react with p-hydroxybenzaldehyde and presented a unique and symmetrical signal at appropriate retention times, allowing an adequate quantification of $\mathrm{INH}$ under the established conditions.

Despite other methods (Balbão et al., 2010; Hee et al., 2015; Khuhawar and Rind, 2002; Walubo et al., 1994), the plasma processing of RIF and INH samples did not require an incubation period, extraction or concentration step, so the process was extremely fast. The runtime for RIF was $12 \mathrm{~min}$, while that for INH was $25 \mathrm{~min}$ and retention times in $\min$ were: $\mathrm{RIF}=7.72$; and $\mathrm{INH}=9.56$. In summary, the samples had an acceptable quantification time. The use of internal standards did not affect the linearity in the concentration ranges used.

Plasma fractionation is a common methodology (Kim et al., 2015; Unsalan et al., 2005; Walubo et al., 1994) since the determination of both analytes in a single chromatographic run is complex. For example, Unsalan et al. (2005) intended a joint quantification of RIF, INH, and pyrazinamide in a unique run. However, the method had to be modified by performing two chromatographic runs which allowed the quantification of INH in one of these and pyrazinamide and RIF in the other.

\section{Selectivity}

The selectivity of the chromatographic system 1 is illustrated in Figure 1, where a complete separation of RIF and RIM can be observed, with a resolution of 3.2. By comparing the blank and plasma samples enriched with RIF and RIM, no interference from the biological matrix below the LLOQ was confirmed. As can be seen in Figure 1B, no signals of INH were observed in the chromatograms of RIF quantification.

The selectivity of the INH chromatographic system 2 is illustrated in Figure 2, where a complete separation of the derivatized compound of INH (INH hydrazone) and AT can be observed, with a resolution of 11.9. By comparing the blank and plasma samples enriched with INH and AT, no interference from the biological matrix below the quantification limit was confirmed. The method was also specific as no interference was found with samples containing RIF (Figure 2B).

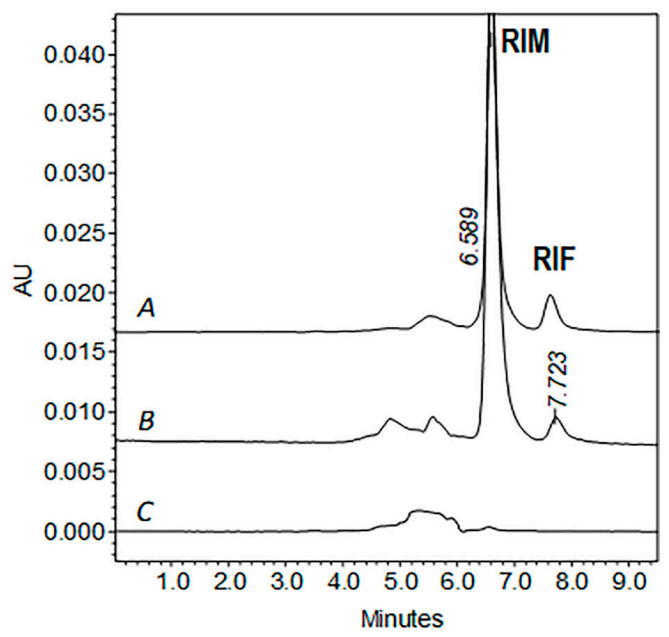

Fig. 1: Representative HPLC-UV overlaid chromatograms of (A) blank plasma sample spiked with rifampicin (RIF) at $1.51 \mu \mathrm{g} / \mathrm{mL}$ and rifamycin (internal standard, RIM) at $26.5 \mu \mathrm{g} / \mathrm{mL}$; (B) blank plasma sample spiked with RIF at $1.67 \mu \mathrm{g} / \mathrm{mL}$, isoniazid at $4.41 \mu \mathrm{g} / \mathrm{mL}$ and RIM at $26.5 \mu \mathrm{g} / \mathrm{mL}$ (C) blank plasma sample. The resolution between RIF and RIM peaks was 3.2.

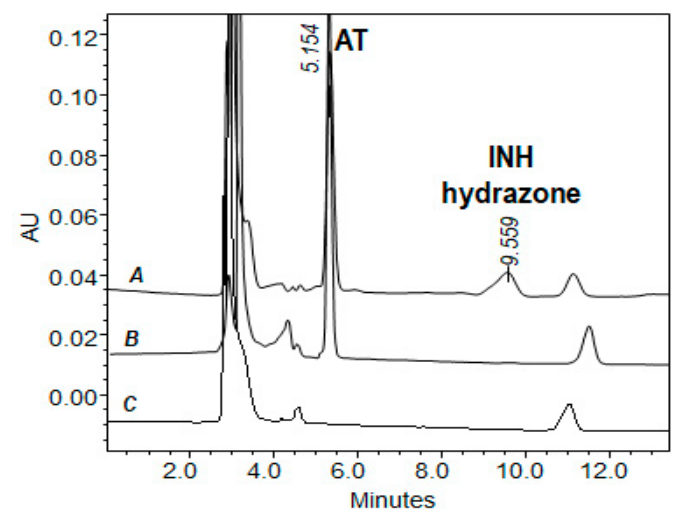

Fig. 2: Representative HPLC-UV overlaid chromatograms of (A) blank plasma sample spiked with isoniazid (INH) at $0.89 \mu \mathrm{g} / \mathrm{mL}$ (LLOQ) and atenolol (internal standard, AT) at $76.68 \mu \mathrm{g} / \mathrm{mL}$; (B) blank plasma sample spiked with rifampicin at $4.41 \mu \mathrm{g} / \mathrm{mL}$ and $\mathrm{AT}$ at $76.68 \mu \mathrm{g} / \mathrm{mL}$ (C) blank plasma sample. The resolution between the INH hydrazone and AT peaks was 11.9.

\section{Linearity, accuracy, precision and lower limit of quantification}

The linearity results are presented in Table 1 and showed a good correlation between the peak relation area of RIF/RIM and INH/AT with the drug concentration, with $\mathrm{r}^{2}$ being greater than 0.9989 for all curves. The calibration curves were linear over 0.16 to $37.80 \mu \mathrm{g} / \mathrm{mL}$ of RIF and 0.89 to $71.36 \mu \mathrm{g} / \mathrm{mL}$ of INH.

As shown in Table 2, the intra-day and inter-day accuracy was within $\pm 15 \%$, and the intra-day and inter-day precision for each level of the tested concentration did not exceed $10.39 \%$ for 
RIF and $8.42 \%$ for INH. The LLOQ was $0.31 \mu \mathrm{g} / \mathrm{mL}$ and $0.89 \mu \mathrm{g} /$ $\mathrm{mL}$ of RIF and INH, respectively.

The LLOQ of RIF and INH were similar to those previously reported for liquid chromatography UV methods (with LLOQ ranging from 0.1 to $0.47 \mu \mathrm{g} / \mathrm{mL}$ of RIF and 0.1 to $1.8 \mu \mathrm{g}$ / mL of INH) (Balbão et al., 2010; Goutal et al., 2016; Khuhawar and Rind, 2002; Melo et al., 2011; Milán-Segovia et al., 2007; Prasanthi et al., 2015). Moreover, this method is more accessible than LC-MS/MS and also offers a simple sample preparation with reliable specificity.

The advantage of this study was the use of a minimal volume of plasma ( $750 \mu \mathrm{L}$ for each full analysis), less than those employed in other similar studies, for example, Walubo et al. (Walubo et al., 1994) used $2000 \mu \mathrm{L}$ and Khuhawar et al. (Khuhawar and Rind, 2002) used $1500 \mu \mathrm{L}$. Therefore, the method presented herein is suitable not only for carrying out pharmacokinetic tests in humans but also in animal models like dogs and baboons (Goutal et al., 2016; Wang et al., 2013).

It is interesting to note that the plasma concentrations expected in a typical $24 \mathrm{~h}$ pharmacokinetic profile post administration of a fixed dose combination of RIF and INH tablets reach $28-30 \mu \mathrm{g} / \mathrm{mL}$ of $\mathrm{RIF}$ and $5-8 \mu \mathrm{g} / \mathrm{mL}$ of $\mathrm{INH}$ in animal models or humans (Agrawal et al., 2001; Wang et al., 2013; Xu et al., 2013). Our method was validated in a concentration range that includes these RIF and INH plasma levels and is more convenient than those proposed by Prasanthi et al. (2015), in which linearity was only ensured at concentrations between 60 to $150 \mu \mathrm{g} / \mathrm{mL}$ of RIF and 40 to $100 \mu \mathrm{g} / \mathrm{mL}$ of INH.

Table 1: Regression parameters for rifampicin (RIF) and isoniazid (INH) calibration standards in human plasma $(0.16$ to $37.80 \mu \mathrm{g} / \mathrm{mL}$ of RIF and 0.89 to $71.36 \mu \mathrm{g} / \mathrm{mL}$ of $\mathrm{INH}$, respectively; $\mathrm{n}=6$ in each case). Data were fitted by linear regression with the least squares method.

\begin{tabular}{ccccc}
\hline & & $\begin{array}{c}\text { Slope } \\
\text { (sensibility) }\end{array}$ & Intercept (blank) & $\mathbf{r}^{\mathbf{2}}$ \\
\hline \multirow{3}{*}{ RIF } & Day 1 & 0.0291 & 0.0005 & 0.9999 \\
& Day 2 & 0.0318 & -0.0054 & 0.9989 \\
& Day 3 & 0.0295 & 0.001 & 0.9995 \\
& Mean \pm SD & $0.030 \pm 0.001$ & $-0.001 \pm 0.004$ & $0.9994 \pm 0.0005$ \\
\hline \multirow{3}{*}{ INH } & Day 1 & 0.0286 & 0.0011 & 0.99994 \\
& Day 2 & 0.0296 & -0.0022 & 0.9992 \\
& Day 3 & 0.0352 & -0.0023 & 0.9996
\end{tabular}

Table 2: Accuracy (bias \%) intra-day and inter-day precision (CV \%) of RIF in the range evaluated.

\begin{tabular}{|c|c|c|c|c|c|c|}
\hline \multirow{2}{*}{ Analyte } & \multirow{2}{*}{$\begin{array}{c}\text { Nominal } \\
\text { concentration }(\mu \mathrm{g} / \mathrm{mL})\end{array}$} & \multirow{2}{*}{$\begin{array}{c}\text { Mean concentration } \\
(\mu \mathrm{g} / \mathrm{mL}) \pm \mathrm{SD} \\
(\mathrm{n}=\mathbf{5})\end{array}$} & \multicolumn{2}{|c|}{ intra-day $(n=5)$} & \multicolumn{2}{|c|}{ inter-day $(n=3)$} \\
\hline & & & Bias (\%) & CV $(\%)$ & Bias (\%) & CV (\%) \\
\hline \multirow{3}{*}{ RIF } & 0.31 & $0.333 \pm 0.002$ & 6.73 & 0.49 & 10.26 & 0.88 \\
\hline & 1.51 & $1.59 \pm 0.07$ & 5.16 & 4.18 & 2.42 & 10.39 \\
\hline & 37.80 & $38 \pm 2$ & 0.02 & 5.80 & 0.96 & 6.92 \\
\hline \multirow{3}{*}{ INH } & 0.89 & $0.82 \pm 0.16$ & 8.29 & 19.47 & 20.08 & 5.34 \\
\hline & 17.84 & $17.8 \pm 0.8$ & 0.03 & 4.46 & 3.02 & 2.65 \\
\hline & 71.36 & $73 \pm 3$ & 2.39 & 4.01 & 1.59 & 1.87 \\
\hline
\end{tabular}

Additionally, since this method was validated in a concentration range embracing therapeutic and sub-therapeutic RIF and INH plasma levels, it could be also convenient for accurate therapeutic drug monitoring of INH and RIF treatment in patients. In fact, it is known that the therapeutic levels of RIF should range between 8 and $24 \mu \mathrm{g} / \mathrm{mL}$ and the dose should be increased when plasma levels fall below $5.6 \mu \mathrm{g} / \mathrm{mL}$ since this value is correlated with therapeutic failure (Alsultan and Peloquin, 2014; Peloquin, 2002).

The use of this method for RIF and INH plasmatic determination in presence of PIR, ETA, or streptomycin, which are drugs usually combined in tuberculosis treatment, should be further explored.

\section{Recovery}

The percentage recoveries of RIF, calculated from three different determinations of two levels (1.67 and $41.79 \mu \mathrm{g} / \mathrm{mL})$ and expressed as mean $\pm \mathrm{CV} \%$ were $(99.6 \pm 11.1) \%$ and $(97.3$ $\pm 11.2) \%$, respectively. For INH, the percentage recoveries were $(96.6 \pm 10.4) \%$ and $(89.8 \pm 2.6) \%$, for samples containing 4.41 and $88.11 \mu \mathrm{g} / \mathrm{mL}$ of INH, respectively.

The recovery of RIF and INH was high and similar in all concentrations studied. Therefore, the proposed extraction method was adequate and reproducible.

\section{Stability}

The RIF and INH human plasma samples were stable after $6 \mathrm{~h}$ of disposition at room temperature in working conditions and remained unchanged for further $24 \mathrm{~h}$ storage in the autosampler after protein precipitation. In addition, RIF plasma samples remained stable after three cycles of freeze/ thawing. Nevertheless, INH plasma samples remained stable only after two cycles of freeze/thawing, since the bias for INH samples of lower concentration in the cycle 3 was greater than $15 \%$ (Table 3 ).

Unlike what happens in acidic aqueous solutions, RIF was more stable in plasma (Alsultan and Peloquin, 2014), because it is highly bounded to proteins (Boman and Ringberger, 1974), and also this medium has a $\mathrm{pH}$ at which hydrolysis of RIF would be minimal. In fact, RIF supported one freeze/thawing cycle more than INH. In consequence, the stability of the RIF and INH plasma samples during the usual processing and quantification times was assured.

In summary, the developed method was a useful analytical tool for the quantification of RIF and INH in pharmacokinetic assays. This method demonstrated a high precision, selectivity, and stability using small volumes of plasma, in agreement with the FDA guideline (FDA, 2001). 
Table 3: Stability of human plasma samples containing RIF and INH $(n=3)$. The acceptance criteria was a bias within $\pm 15 \%$.

\begin{tabular}{|c|c|c|c|c|c|c|}
\hline \multirow{2}{*}{ Analyte } & \multirow{2}{*}{ Nominal concentration $(\mu \mathrm{g} / \mathrm{mL})$} & \multirow{2}{*}{$\begin{array}{l}\text { Short-term stability } \\
\text { (bias; \%) }\end{array}$} & \multicolumn{3}{|c|}{ Freeze-thaw stability (bias; \%) } & \multirow{2}{*}{$\begin{array}{c}\text { Post-preparative stability } \\
\text { (bias; \%) }\end{array}$} \\
\hline & & & Cycle 1 & Cycle 2 & Cycle 3 & \\
\hline \multirow{2}{*}{ RIF } & 1.67 & 0.23 & 0.12 & 0.08 & 0.00 & 0.01 \\
\hline & 41.79 & 0.01 & 2.48 & 2.96 & 4.19 & 0.35 \\
\hline \multirow{2}{*}{ INH } & 4.41 & 8.6 & 12.5 & 15.4 & 18.6 & 13.3 \\
\hline & 88.11 & 4.2 & 0.3 & 3.6 & 4.4 & 12.2 \\
\hline
\end{tabular}

\section{CONCLUSIONS}

This paper describes a reproducible HPLC method which enables the determination of RIF and INH in plasma samples. The sample preparation method was simple since it requires only a protein precipitation without needing either an extraction or concentration step.

The chromatographic systems developed using an isocratic method and UV detection showed good selectivity, robustness, and stability, and are suitable for a reliable determination of these compounds. The HPLC assay methods presented here could be successfully applied to the determination of the pharmacokinetic profiles after oral administration of fixed dose combination tablets of RIF and INH, with a potential applicability in the drug monitoring of tuberculosis treatment.

\section{ACKNOWLEDGMENTS}

This work was supported by grants from Consejo Nacional de Investigaciones Científicas y Técnicas (CONICET PIP 2013-2015, number 11220120100761), the Agencia Nacional de Ciencia y Tecnología (FONCyT, PICT-2012-0173) and the Secretaría de Ciencia y Técnica de la Universidad Nacional de Córdoba (SECyT-UNC), Argentina.

The authors wish to acknowledge the assistance of the Consejo Nacional de Investigaciones Científicas y Técnicas (CONICET) and the Universidad Nacional de Córdoba, both of which provided support and facilities for this investigation and also to Dr. Andrea Breda for her help in the HPLC assays.

\section{CONFLICTS OF INTEREST}

The authors declare that they have no conflict of interest.

\section{REFERENCES}

Agrawal S, Kaul CL, Panchagnula R. Bioequivalence of isoniazid in a two drug fixed dose combination and in a single drug dosage form. Pharmazie, 2001; 56:636-639.

Agrawal S, Panchagnula R. Implication of biopharmaceutics and pharmacokinetics of rifampicin in variable bioavailability from solid oral dosage form. Biopharm. Drug Dispos, 2005; 26:321-334. doi: 10.1002/ bdd.464.

Ahmad Z, Pandey R, Sharma S, Khuller GK. Pharmacokinetic and pharmacodynamic behaviour of antitubercular drugs encapsulated in alginate nanoparticles at two doses. Int J Antimicrob Agents, 2006; 27:409416. doi: 10.1016/j.ijantimicag.2005.12.009.

Alsultan A, Peloquin CA. Therapeutic drug monitoring in the treatment of tuberculosis: An update. Drugs, 2014; 74:839-854. doi: 10.1007/s40265-014-0222-8.

Avachat AM, Bhise SB. Tailored release drug delivery system for rifampicin and isoniazid for enhanced bioavailability of rifampicin. Pharm Dev Technol, 2011; 16:127-36. doi: 10.3109/10837450903511186.

Balbão MS, Bertucci C, Bergamaschi MM, Queiroz RHC,
Malfará WR, Dreossi SAC, de Paula Mello L, Queiroz MEC. Rifampicin determination in plasma by stir bar-sorptive extraction and liquid chromatography. J Pharm Biomed Anal, 2010; 51:1078-1083. doi: 10.1016/j.jpba.2009.11.001.

Becker C, Dressman JB, Junginger HE, Kopp S, Midha KK, Shah VP, Stavchansky S, Barends DM. Biowaiver Monographs for Immediate Release Solid Oral Dosage Forms: Rifampicin. J Pharm Sci, 2009; 98:22522267. doi: $10.1002 /$ jps.21624.

Beltrame S, Latorraca M, Moral M. 2014. Enfermedades infecciosas. Tuberculosis. GUIA PARA EL EQUIPO DE SALUD, 2nd ed. Buenos Aires, Argentina: Dirección de Epidemiología - Ministerio de Salud de la Nación.

Boman G, Ringberger VA. Binding of rifampicin by human plasma proteins. Eur J Clin Pharmacol, 1974; 7:369-373. doi: 10.1007/ BF00558209.

Chellini PR, Lages EB, Franco PHC, Nogueira FHA, César IC, Pianetti GA. Development and validation of an HPLC method for simultaneous determination of rifampicin, isoniazid, pyrazinamide, and ethambutol hydrochloride in pharmaceutical formulations. J AOAC Int, 2015; 98:1234-1239. doi: 10.5740/jaoacint.14-237.

Desai D, Shah M. A Review: Validated analytical methods developed on antitubercular drug Rifampicin. J Pharm Sci Biosci Res, $2015 ; 5: 254-265$.

FDA, 2001. Guidance for Industry Bioanalytical Method Validation. Rockville MD, USA; Department of Health and Human Services (FDA), Center for Drug Evaluation and Research (CDER) and Center for Veterinary Medicine (CVM).

Goutal S, Auvity S, Legrand T, Hauquier F, Cisternino S, Chapy H, Saba W, Tournier N. Validation of a simple HPLC-UV method for rifampicin determination in plasma: Application to the study of rifampicin arteriovenous concentration gradient. J Pharm Biomed Anal, 2016; 123:173-178. doi: 10.1016/j.jpba.2016.02.013.

Gupta RN. Determination of isoniazid in plasma by liquid chromatography. J Chromatogr Biomed Appl, 1988; 425:441-443.

Hee KH, Seo JJ, Lee LS. Development and validation of liquid chromatography tandem mass spectrometry method for simultaneous quantification of first line tuberculosis drugs and metabolites in human plasma and its application in clinical study. J Pharm Biomed Anal, 2015; 102:253-260. doi: 10.1016/j.jpba.2014.09.019.

Khuhawar MY, Rind FMA. Liquid chromatographic determination of isoniazid, pyrazinamide and rifampicin from pharmaceutical preparations and blood. J Chromatogr B Anal Technol Biomed Life Sci, 2002; 766:357-363. doi: 10.1016/S0378-4347(01)005102.

Kim H-J, Seo K-A, Kim H-M, Jeong E-S, Ghim JL, Lee SH, Lee YM, Kim DH, Shin J-G. Simple and accurate quantitative analysis of 20 anti-tuberculosis drugs in human plasma using liquid chromatographyelectrospray ionization-tandem mass spectrometry. J Pharm Biomed Anal, 2015; 102:9-16. doi: 10.1016/j.jpba.2014.08.026.

Lu Y, Duanmu H, Wang L. 2017. Handbook of Global Tuberculosis Control: Practices and Challenges. New York, USA: Springer.

Melo LP, Queiroz RHC, Queiroz MEC. Automated determination of rifampicin in plasma samples by in-tube solid-phase microextraction coupled with liquid chromatography. J Chromatogr B Anal Technol Biomed Life Sci, 2011; 879:2454-2458. doi: 10.1016/j.jchromb.2011.06.041. 
Milán-Segovia R, Pérez-Flores G, Torres-Tirado JD, HermosilloRamírez X, Vigna-Pérez M, Romano-Moreno S. Simultaneous HPLC determination of isoniazid and acetylisoniazid in plasma. Acta Chromatogr, 2007; 110-118.

Ministerio de Salud, Secretaría de Políticas Regulación e Institutos, Administración Nacional de Medicamentos Alimentos y Tecnología Médica, Instituto Nacional de Medicamentos. 2003. Farmacopea Argentina [Internet]. 7th ed. Comisión Permanente de la Farmacopea Argentina, editor. Ciudad Autónoma de Buenos Aires. Available from: http://www.anmat.gov.ar/webanmat/fna/fna.asp.

Panchagnula R, Sood A, Sharda N, Kaur K, Kaul CL. Determination of rifampicin and its main metabolite in plasma and urine in presence of pyrazinamide and isoniazid by HPLC method, 1999; 18:10131020 .

Peloquin CA. Therapeutic Drug Monitoring in the Treatment of Tuberculosis, 2002; 62:2169-2183.

Prasad B, Singh S. In vitro and in vivo investigation of metabolic fate of rifampicin using an optimized sample preparation approach and modern tools of liquid chromatography-mass spectrometry. J Pharm Biomed Anal, 2009; 50:475-490. doi: 10.1016/j.jpba.2009.05.009.

Prasanthi B, Ratna JV, Phani RSC. Development and validation of RP-HPLC method for simultaneous estimation of rifampicin, isoniazid and pyrazinamide in human plasma. J Anal Chem, 2015; 70:1015-1022. doi: $10.1134 / \mathrm{S} 1061934815080146$.

Schellinger AP, Carr PW. Isocratic and gradient elution chromatography: A comparison in terms of speed, retention reproducibility and quantitation. J Chromatogr A, 2006; 1109:253-266. doi: 10.1016/j. chroma.2006.01.047.

Singh S, Bhutani H, Mariappan TT. Quality Problems of AntiTuberculosis Fixed-Dose Combinations (Fdes): a Way Forward. Indian J Tuberc, 2006; 53:201-205.

Unsalan S, Sancar M, Bekce B, Clark PM, Karagoz T, Izzettin FV, Rollas S. Therapeutic Monitoring of Isoniazid, Pyrazinamide and Rifampicin in Tuberculosis Patients Using LC. Chromatographia, 2005; 61:595-598. doi: 10.1365/s10337-005-0549-0.
Verbeeck RK, Günther G, Kibuule D, Hunter C, Rennie TW. Optimizing treatment outcome of first-line anti-tuberculosis drugs: the role of therapeutic drug monitoring. Eur J Clin Pharmacol, 2016; 72:905-916. doi: 10.1007/s00228-016-2083-4.

Walubo A, Smith P, Folb PI. Comprehensive assay for pyrazinamide, rifampicin and isoniazid with its hydrazine metabolites in human plasma by column liquid chromatography. J Chromatogr B Biomed Sci Appl, 1994; 658:391-396. doi: 10.1016/0378-4347(94)00230-4.

Wang Y, Liu H, Liu K, Sun J, He Z. Design and evaluation of enteric-coated tablets for rifampicin and isoniazid combinations. Pharm Dev Technol, 2013; 18:401-6. doi: 10.3109/10837450.2012.659254.

World Health Organization. 2016. WHO treatment guidelines for drug-resistant tuberculosis. Geneva, Switzerland: The WHO.

World Health Organization. 1997. Tratamiento de la Tuberculosis: Directrices para los programas nacionales, 2nd ed, Serie de Informes Técnicos. Geneva, Switzerland: The WHO.

Xu J, Jin H, Zhu H, Zheng M, Wang B, Liu C, Chen M, Zhou L, Zhao W, Fu L, Lu Y. Oral Bioavailability of Rifampicin, Isoniazid, Ethambutol, and Pyrazinamide in a 4-Drug Fixed-Dose Combination Compared With the Separate Formulations in Healthy Chinese Male Volunteers. Clin Ther, 2013; 35:161-168.

Zhou Z, Chen L, Liu P, Shen M, Zou F. Simultaneous determination of isoniazid, pyrazinamide, rifampicin and acetylisoniazid in human plasma by high-performance liquid chromatography. Anal Sci, 2010; 26:1133-1138. doi: 10.2116/analsci.26.1133.

How to cite this article:

Luciani-Giacobbe LC, Guzman ML, Manzo RH, Olivera ME. Validation of a simple isocratic HPLC-UV method for rifampicin and isoniazid quantification in human plasma. J App Pharm Sci, 2018; 8(07): 093-099. 